\title{
Virtual Blood and Sperm Bank for Dogs
}

\author{
Dr.Mahesh kaluti ${ }^{1}$, Tejas kumar $\mathrm{N}^{2}$, Vikas chandra guru ${ }^{3}$, Rajath $\mathrm{S}^{4}$, SHIVRAJ $\mathrm{S}^{5}$ \\ ${ }^{1}$ (Associate Professor, Department of computer science and engineering, \\ 2,3,4,5 (Department of computer science and engineering, \\ P.E.S College of Engineering mandya, Karnataka, India)
}

\begin{abstract}
Virtual blood bank is the online based management system. allows online ordering, request delivery of blood for transfusion. sperm bank, semen bank is a facility to enhance the interface of purchasing and selling DOG semen. This project presents a bridge the gap between the blood donors and the request dog for blood. The requirement of the blood has to be requested and we supply the information of the donor through a simple online based management system.
\end{abstract}

Keywords:- Blood Drive, Blood Mobile, Blood Donor Centre, Sperm Depository, Rudhir-Adhikosha.

\section{INTRODUCTION}

Dogs consist of 12 types of blood group 40 percentage of dogs are given DEA1.1 the first time of blood transfusion can be given to any type of dogs but on the second time of transfusion of blood the blood should be given to the same type of blood group lately discovered in Dal blood group Dalmatians. Dalmatians types of dog these can donate only to themselves not to any of the other breed and if this application of blood and sperm bank donor application surely helps each and every dogs like dalmatians Semen collection refers to the process of obtaining semen from male dog can be helped in also other ways seeking through the nearest becomes much more easier by seeking all the information which has existed and making sure the life of all the animals are secure by this project.

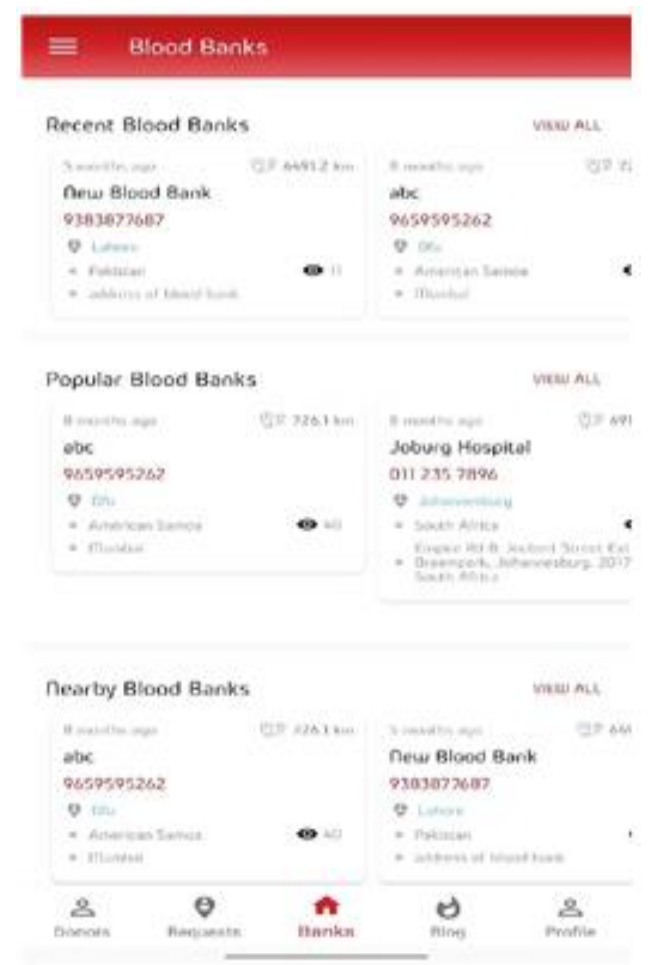

Fig 1:- snapshot of blood bank application hospital.

PAPER :- 1 COMPUTERIZED

CENTRAL BLOOD BANK

MANAGEMENT SYSTEM

(CCBMS).2018 international conference on computer, control, electrical and electronics engineering (icc eee).how to implement blood. 

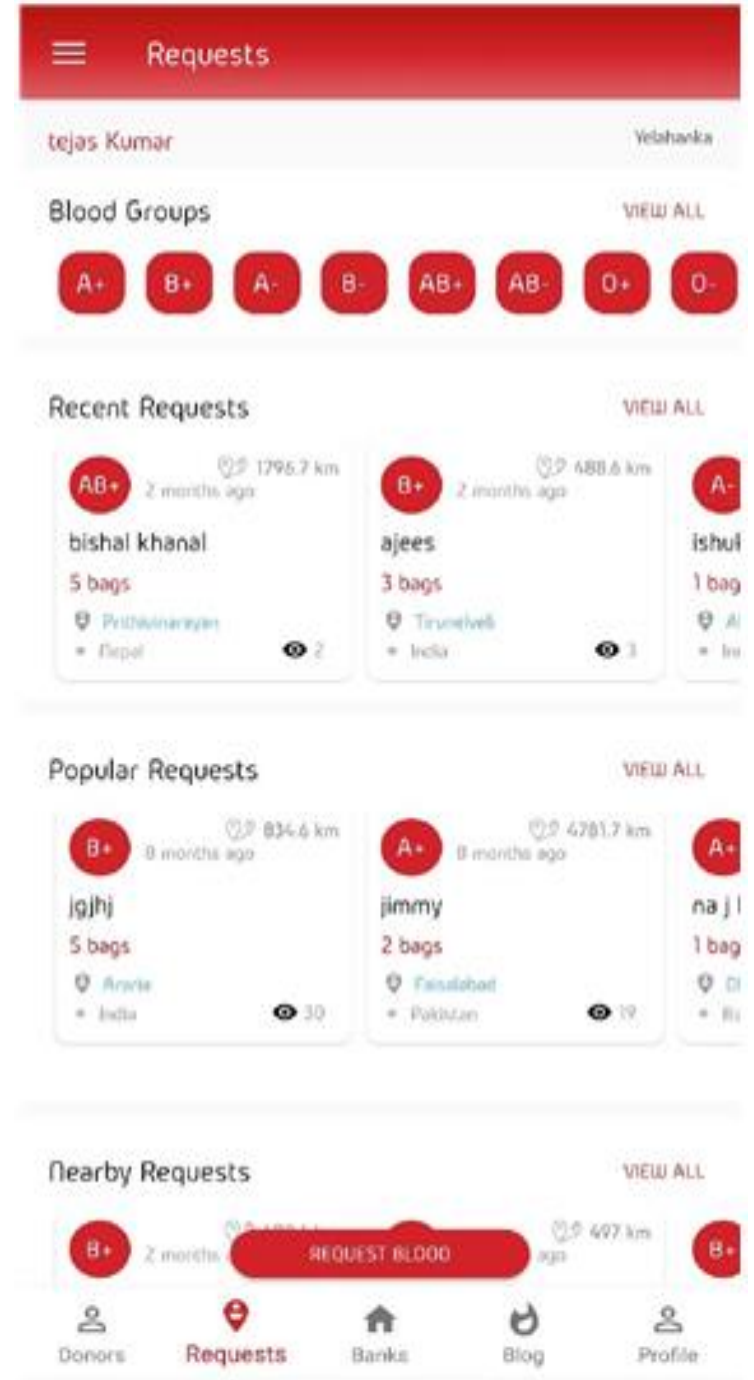

Fig 2:- snapshot request page of mobile application

\section{PAPER :- 2 IOT BASED SMART \\ NETWORK FOR BLOOD BANK.2018}

7 th international conference on reliability, infocom technologies and optimization (icrito).

Analysis in which the internet can be used by each and every pet lover and animal lover certainly to save their dogs and this tends to help each and every dogs so that the analysis could be made easier so that process will be updated as fast as possible and it helps the nature to be in peace so that the analysis of each and every dog are fit safe and healthy from all kind of disease and free from all types of virus and which tends to help the owners from panicking overall it is a easy way to execute and make sure have a healthy planet.

\section{ANALYSIS AND LITERATURE SURVEY}

Literature survey in which the existing project is taken to the development of the future by analysing the process and the future.

\section{DESIGN WORKS}

The design phase is a phase so that it shows the look and function or workings of building the application or other object before it is made. The design phase is based upon making a detailed process of application as a result of plan the of a required application of blood and sperm bank of dogs is been designed in the flow of a required solution to the given problem this plays a major role in the application development process it has a major impact on the phases like particularly in testing. The design activity often results in separate outputs .

Architecture of a particular design of modern application development depends on the art or practice of designing and constructing buildings of a particular design of application.

The application of blood and sperm bank is based on the the request of blood page contains the information of request dog information and the donor dog donates to the request $\operatorname{dog}$ so that the dog could be saved in all aspect and it contains the current live location of the request blood for the dog so that the nearer donor can help the requested dog and this plays an important role in the design phase and there are many more aspects in which the dogs lives are saved and the bank of the application of blood and sperm bank contains the information of each and every dog which is been logged in by the owner of a particular method.

\section{EXPERIMENTAL RESULT}

Experiment results are correct without any obstacles our application is being processed under good circumstances. The application is being built in a way the future would be happier for all the pet lovers and to save mother nature in each and every aspect of a given condition.
Recent Donors

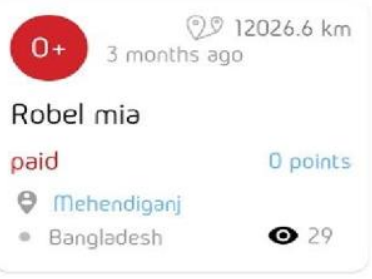

VIEW ALL

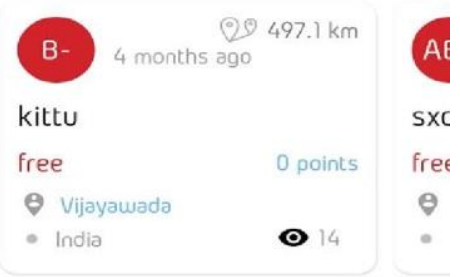

Fig 3:- Experimental Snapshot of donors

\section{CONCLUSIONS}

This report presents, the pet lovers who are suffering to save their dogs can be easily saved by this kind of analysis and design and it is not only about dogs by this way each and every animals can be saved without panicking and each and every living beings can be lived happily through their respective lives happily hence this kind of effort can help a lot to save the mother nature. 


\section{REFERENCES}

[1]. Atkinson, M. P.; Fontaine, M. J.; Goodnough, L. T.; Wein, L. M. (2012). "A novel allocation strategy for blood transfusions: Investigating the tradeoff between the age and availability of transfused blood" (PDF).

[2]. Transfusion. "Circular of Information for the use of Human Blood and Blood Components" (PDF). AABB, ARC, America's Blood Centers. p. 16. Archived from the original (PDF) on October 7, 2009.

[3]. Retrieved 2010-10-18. Devine, D. V.; SAdam, David (2004-05-27). "How long can frozen sperm be stored?".the Guardian. Retrieved 2018-04-14."Sperm freezing |

[4]. Fertilisation and Embryology Authority". www.hfea.gov.uk. Retrieved 2018-04-14. Almeling, Rene. American Sociological

[5]. Review. Vol. 72, No. 3 (Jun 2007), pp. 319-340.

[6]. "CELLS, TISSUES, AND CELLULAR AND TISSUE-BASED PRODUCTS". CFR - Code of Federal Regulations. "The sperm-donation business". The Economist. Retrieved 29 October 2017.errano, K. (2010). "The Platelet Storage Lesion. 